PPPL-3231, Prinprint: February 1997, UC-420

\title{
Alpha-Driven Magnetohydrodynamics (MHD) and MHD-Induced Alpha Loss in the Tokamak Fusion Test Reactor
}

Z. Chang, R. Nazikian, G.-Y. Fu, R. B. White, S. J. Zweben, E. D. Fredrickson, S. H. Batha ${ }^{1}$, M. G. Bell, R. E. Bell, R. V. Budny, C. E. Bush ${ }^{2}$, L. Chen ${ }^{3}$, C. Z. Cheng, D. Darrow, B. LeBlanc, F. M. Levinton ${ }^{1}$, R. P. Majeski, D. K. MansÆeld, K. M. McGuire, H. K. Park, G. Rewoldt, E. J. Synakowski, W. M. Tang, G. Taylor, S. von Goeler, K. L. Wong, L. Zakharov and TFTR group

Plasma Physics Laboratory, Princeton University, Princeton, New Jersey 08543, USA

${ }^{1}$ Fusion Physics and Technology, Torrance, California 90503, USA

${ }^{2}$ Oak Ridge National Laboratory, Oak Ridge, Tennessee 08731, USA

${ }^{3}$ Department of Physics, University of California, Irvine, California 92717-4575, USA

(Dec. 16, 1996)

Invited talk at the 1996 APS-DPP meeting, Denver Accepted for publication in it Physisc of Plasmas 


\section{DISCLAIMER}

This report was prepared as an account of work sponsored by an agency of the United States Government. Neither the United States Government nor any agency thereof, nor any of their employees, makes any warranty, express or implied, or assumes any legal liability or responsibility for the accuracy, completeness, or usefulness of any information, apparatus, product, or process disclosed, or represents that its use would not infringe privately owned rights. Refereace herein to any specific commercial product, process, or service by trade name, trademark, inanufacturer, or otherwise does not necessarily constitute or imply its endorsement, recommendation, or favoring by the United States Government or any ageacy thereof. The views and opinions of authors expressed herein do not necessarily state or refiect those of the United States Government or any agency tbereof. 


\section{DISCLAIMER}

Portions of this document may be illegible in electronic image products. Images are produced from the best available original document. 


\begin{abstract}
Alpha-driven toroidal Alfven eigenmodes (TAEs) are observed as predicted by theory in the post neutral beam phase in high central $q$ (safety factor) deuterium-tritium (D-T) plasmas in the Tokamak Fusion Test Reactor (TFTR) [D. J. Grove and D. M. Meade, Nucl. Fusion 25, 1167 (1985)]. The mode location, poloidal structure and the importance of $q$ proAle for TAE instability are discussed. So far no alpha particle loss due to these modes was detected due to the small mode amplitude. However, alpha loss induced by kinetic ballooning modes (KBMs) was observed in high-conÆnementDT discharges. Particle orbit simulation demonstrates that the wave-particle resonant interaction can explain the observed correlation between the increase in alpha loss and appearance of multiple high- $n(n \geq 6, n$ is the toroidal mode number) modes.
\end{abstract}

PACS numbers: 52.55.Pi 52.35.-g 52.35.Py 52.65.Cc 


\section{INTRODUCTION}

In a burning plasma such as ITER (International Thermonuclear Experimental Reactor [1]), MHD (magnetohydrodynamic) instabilities can potentially cause the 3.5 MeV fusion alpha particles to be lost before they thermalize [2]. Signi/Ecant loss of energetic alphas may inhibit ignition or damage the Erstwall of the reactor.

Among many possible MHD modes, the alpha-driven toroidal Alfven eigenmodes (TAEs) [3] are theoretically predicted to be the most dangerous [4]. To test the theory and to study the alpha-driven TAE ( $\alpha$-TAE) in D-T plasmas, an extensive search for the $\alpha$-TAE has been undertaken in TFTR D-T experiments $[5,6,7]$. The lack of observed $\alpha$-TAE in high fusion power D-T experiments ( $P_{\text {fusion }} \lesssim 10.7 M W$ and $\beta_{\alpha} \lesssim 0.3 \%$, where $\beta_{\alpha}$ is the ratio of alpha pressure to magnetic pressure) has led to important modiÆcationsto the TAE theories. These improvements in theoretical modeling have led to a prediction of the $\alpha$-TAE in the post neutral-beam-injection phase [8]. Recently, such $\alpha$-TAEs have indeed been observed [9]. Section II shows some of the detailed observation and theoretical calculations. So far no correlated alpha particle loss is observed associated with the $\alpha$-TAE activity.

However, alpha loss due to a similar wave-particle resonance was observed in some other high-performance D-T discharges where kinetic-ballooning-modes (KBM) [10] were excited due to the strong plasma pressure gradient [11]. Study of the loss mechanism using a particle simulation code provides interesting insight into the particle-wave interaction. This KBM-induced alpha particle loss is discussed in Section III. Discussion and conclusions are given in Section IV.

\section{ALPHA-DRIVEN TOROIDAL ALFVEN EIGENMODE (TAE)}




\section{A. Theoretical prediction}

To destabilize a TAE, the alpha drive or growth rate $\left(\gamma_{\alpha}\right)$ needs to exceed the total damping rate $\left(\gamma_{d}\right)$. The growth rate is proportional to the alpha pressure (or $\beta_{\alpha}=2 \mu_{0} P_{\alpha} / B^{2}$, where $P_{\alpha}$ is the alpha pressure, $B$ is the magnetic Eeld). Also, the resonant condition $V_{\alpha} \sim V_{A}$ needs to be satisÆed, where $V_{\alpha}=\sqrt{2 E_{\alpha} / m_{\alpha}}, E_{\alpha}$ is the alpha energy, $m_{\alpha}$ is the alpha mass, and $V_{A}$ is the Alfven velocity given by $V_{A}=B / \sqrt{4 \pi \Sigma_{i} m_{i} n_{i}}$, where $\dot{m}_{i}$ and $n_{i}$ are the ion atomic mass and density. The damping rate is a sum over various damping mechanisms ranging from velocity space Landau damping to geometry related processes such as radiative damping, trapped electron collisional damping, Alfven continuum damping, etc. (for example, see discussion in Ref. [8]). Numerical analysis using the NOVA-K code [12] shows that for the $\beta_{\alpha}$ values $(\leqslant 0.3 \%$ ) achieved in TFTR, the plasma should be stable to the $\alpha$-TAE during the neutral beam phase, mainly due to the strong beam-ion Landau damping. However, after the neutral beam (NB) turned off, the ratio of growth rate to damping rate becomes dramatically reduced. This is primarily due to the much longer slowing down time for alpha particles $(\sim 0.5 \mathrm{sec})$ than for the beam ions $(\leqslant 0.1 \mathrm{sec})$. Therefore, $\alpha$-TAEs are most likely to be transiently excited in the post beam phase. However, the fact that the $\alpha$-TAE has not been previously seen in the post-beam phase of normal D-T supershot plasmas implies that some other factor(s) is involved. Recent numerical analyses showed that plasmas with low central magnetic shear [8] $s \equiv(r / q) d q / d r$ and high central $q$ [13] are more unstable, mainly because of a wider TAE gap (less Alfven continuum damping) and a larger distance between gaps (less radiative damping) in such a magnetic geometry.

An experiment motivated by these theoretical predictions successfully excited 
the $\alpha$-TAE. The experiment and Erstobservations have been described in Ref. [9]. In the following we will show additional experimental data and further discuss the physics of the $\alpha$-TAE.

\section{B. Basic observations}

The post-beam $\alpha$-TAEs have been observed in two types of plasmas [9]. The Ersttype is characterized by large major radius $R=2.60 \mathrm{~m}$, plasma current $I_{p}=1.6$ MA, and higher central $q, q_{0} \gtrsim 2$ (we call this the high- $q_{0}$ plasma). The second type of plasma has smaller major radius $R=2.52 \mathrm{~m}$, higher plasma current $I_{p}=2.0$ MA, and lower central $q, q_{0} \gtrsim 1$ (we call this the low- $q_{0}$ plasma). Figure 1 shows one discharge of each type. The TAE modes are consistently seen in the $100-300$ ms window after the neutral beam (NB) termination. The $q$ proÆlesduring the NB phase are measured by a Motional Stark Effect (MSE) diagnostic [14]. In the postbeam phase, they are either calculated by the transport simulation code TRANSP [15] based on measured plasma proÆles,or from an interpolation of the MSE data measured in the main NB phase and the diagnostic beam blip phase at 3.05-3.1 sec. It is important to note that the central $q$ in both cases is higher than the conventional supershot plasmas where $q_{0} \simeq 0.8$. The fusion power in the high- $q_{0}$ plasmas is a factor of 2 lower than the low- $q_{0}$ plasmas, see Fig. 1(b). The peak fusion power in the discharge where $\alpha$-TAE is detected is as low as $1.75 \mathrm{MW}$ (with $P_{B}=24 \mathrm{MW}$ ). The post-beam TAE was Erstobserved in a neutral beam plus ICRF (ion-cyclotron range of frequencies heating) D-T experiment, where the fusion power was only about $1 \mathrm{MW}$. However, due to the existence of the minority tail ions, the analysis of these ICRF discharges was more complicated. .

The TAEs were detected by the external magnetic coils (Mirnov coils [16]) and by the internal reØectometer diagnostic [9] for the strongest modes. The observed 
dominant TAE has toroidal mode number $n=3$. The TAE amplitude at the edge is about 0.4-0.5 mGauss, or $\tilde{B}_{p} / B_{0} \simeq 1 \times 10^{-8}$. Although the TAE amplitudes are about the same in both plasmas [Fig.1(d)], the the background magnetic turbulence level in the high- $q_{0}$ large- $R$ discharges is about 0.2 mGauss, while in the low- $q_{0}$ small- $R$ cases is only about 0.05 mGauss. (This is mainly due to the difference in the distance between the plasma and the magnetic coils.) Except for some weak low frequency $n=1$ external MHD, no signiÆcantcoherent MHD activity was observed in these plasmas. In contrast to the usual supershot plasmas, the $n=1$ Æshbone-typemodes are absent due to $q_{0}>1$ in these plasmas.

\section{Mode location and frequency evolution}

The mode location is crucial for TAE identiÆcation. The mode shown as the dashed curves in Fig. 1(d) and (e) was detected by a core microwave reØectometer diagnostic at $r / a \simeq 0.42$, and not seen in the outer channel at $r / a \simeq 0.57$. Due to the limited number of reØectometer channels, this measurement does not determine the spatial location of the TAE. The mode location can be estimated from a comparison between the TAE frequency and plasma density due to the Alfven feature of these modes. This method has previously been used to identify the location of the Alfven frequency mode (AFM) [17]. Shown in Fig. 2(a) are the time traces of the electron density at different radii measured by the multichannel infrared interferometer. A small edge event happened at $3.01 \mathrm{sec}$ that caused a sudden increase in the edge density. The propagation of this perturbation to the core can be clearly seen. Corresponding to this event the edge AFM shows a sharp drop in frequency, see Fig. 2(b). On the other hand, the n=3 TAE, shown in Fig. 2(c), does not show such an instantaneous response. Instead, there is a rollover which correlates with the core density changes. Using the TAE frequency deÆni- 
tion, $f_{T A E} \simeq V_{A} / 4 \pi q R \propto B / R q \sqrt{n_{e}}$ we can locate the mode from the correlation between the mode frequency and the density. As shown in Fig. 2(c) the mode location determined by this method is $0.25 \lesssim r / a \lesssim 0.45$. This result is consistent with the reØectometer measurement.

\section{Mode poloidal structure}

An interesting and somewhat puzzling observation in the $\alpha$-TAE experiment is the poloidal mode structure. Figure 3(a) shows the poloidal variation of the $\mathrm{n}=3$ TAE amplitude measured from the Mirnov coil array. (Note that the mode amplitude shown in Fig. 1 is from the toroidal array at $\theta \simeq-65^{\circ}$.) The mode is strongly peaked around the high Æeldside, that is, it has an TManti-ballooning character. This feature is seen for TAEs in both $R=2.60 \mathrm{~m}$ and $R=2.52 \mathrm{~m}$ plasmas. This is very different from the mode structure observed in the ICRF-driven TAEs shown in Fig. 3(b), where the modes are ballooning or weakly-ballooning. For another comparison, Fig. 3(c) shows the mode structure for the high- $n(=6)$ kinetic ballooning mode (KBM), to be discussed in Section III. Of course, this result may not reØect the real mode structure inside the plasma. However, if this in-out asymmetry were intrinsic, it might indicate that the observed $\alpha$-TAE is the so-called TMOdd-AE or kinetic TAE (K-TAE) as predicted in Ref. [18]. On the other hand, as shown in Ref. [9] the observed mode frequencies are systematically located near the bottom of the TAE gap. This implies that the modes are more likely to be the TMeven- $\mathbb{A E}$ [19]. Also, NOVA-K calculations seem also to indicate that the even-TAE is more unstable than the odd-TAE [20].

Another interesting observation is the sequence in which the different mode numbers appear. In the low- $q_{0}$ discharge (95796), the $n=4$ mode appears Erstand is followed by $n=3$, and then by $n=2$, see Fig. 2 . However, in a high- $q_{0}$ discharge, 
the sequence is $n=2,4$, and 3. Comparing with the ICRF-driven TAE, we found that the ICRF-TAEs often have multiple modes even at similar low mode amplitudes as the $\alpha$-TAE.

\section{E. Statistical observations}

Observation of the $\alpha$-TAE in these relatively low fusion power plasmas also raises a question: Why are the post-beam TAEs only observed in these plasmas but not in other higher fusion power supershot discharges? As shown in Fig. 4(a), the achieved $\beta_{\alpha}(0)(140 \mathrm{~ms}$ after the NB phase) in $\alpha$-TAE discharges is generally smaller than the supershot plasmas even with the same maximum fusion power. The most striking feature of $\alpha$-TAE discharges is the elevated central $q$ (or low shear in the core) as shown in Fig. 4(b). First of all, the threshold $\beta_{\alpha}(0)$ for $\alpha$-TAE is a factor of 2 lower in the high- $q_{0}$ case than in the low- $q_{0}$ case. All the regular supershot plasmas have $q_{0}<1$. Obviously, the $\beta_{\alpha}$ is also important. TAEs are not observed in some high- $q_{0}(\sim 1.5)$ discharges when the $\beta_{\alpha}$ is low, see Fig. 4(b). However, $\alpha$-TAE has not been observed in reversed magnetic shear [21] plasmas in which the $q_{0}$ is even higher. This fact indicates that the $q_{0}$ is not the only parameter that determines the $\alpha$-TAE regime.

Numerical calculation using NOVA-K code shows that the most important parameter that determines the post-beam $\alpha$-TAE is the $q$ proÆle. As discussed in Ref. [9], the low-shear/high- $q$ con Egurationleads to a wider TAE gap structure across

the plasma radius. Also, due to the low shear the ratio of $\gamma_{\alpha} / \gamma_{d}$ is systematically higher in the $\alpha$-TAE discharges than in the comparison supershot plasmas. Even for the $\alpha$-TAE discharges, this ratio can change dramatically for slight changes of $q(0)$ (or of the central $q$ proÆlein general). Obviously, a Æner $q(0)$ scan is needed to further investigate this central $q(r)$ sensitivity for $\alpha$-TAE. 


\section{F. TAE and alpha loss}

The ultimate goal of the $\alpha$-TAE experiment is to study alpha conÆnement physics. However, no enhanced loss was so far observed due to these $\alpha$-TAE. By comparing the amplitude of these $\alpha$-TAEs with other observed TAEs (ICRFTAE [22] and NB-TAE [23]), we found that the absence of measurable alpha loss can be mainly attributed to the weakness of the mode. According to the experimental scaling between the fast ion loss and the TAE amplitude [24], the present level of $\alpha$-TAE is near or below the detection limit.

\section{KBM-INDUCED ALPHA LOSS}

The Ærstobservation of the KBM-induced alpha loss has been described in Ref. [11]. Correlation between the high- $n$ modes and alpha loss enhancement was observed in both single-mode and multiple-mode cases. Here, we will mainly discuss the multiple-mode case, which correlates with much larger alpha loss than the single-mode case, and which was not simulated in Ref. [11].

\section{A. Basic observation}

A factor of 2 enhancement in fusion alpha loss was observed in some Lithiumaided high- $\beta$ D-T supershot discharges [25], which correlates with occurrence of high frequency high-n MHD modes. The correlation is shown in Fig. 5(a) and (b). The escaping alphas are detected by scintillator probes [26] located at $90^{\circ}$, $60^{\circ}$ and $45^{\circ}$ below the outboard midplane. Shown in Fig. 5(a) is the alpha particle $\varnothing u x$ to the $90^{\circ}$ probe normalized to the neutron yield. The high frequency modes are detected by both the 20-channel ECE polychromator [27] and Mirnov coil diagnostics. Figure 5(b) shows the contour plot of the frequency spectrum measured 
from one $\mathrm{ECE}$ detector at $r / a \simeq 0.40$. The frequencies of these modes are well below the TAE frequency, which is in the range of $V_{A} / 4 \pi q R \simeq 290-310 \mathrm{kHz}$ for $r / a=0.2-0.4$ at $t=4.3-4.5 \mathrm{sec}$. Among the quasi-continuous MHD modes with $n=1-11$, only those with high $n(\geq 6)$ are found to correlate with the lost alpha bursts. This selective behavior indicates that the loss is due to direct wave-particle resonance, rather than being due to the stochasticity induced by low frequency MHD, which has also been previously observed in TFTR D-T experiments [28].

\section{B. KBM mode structure}

The multiple- $n$ modes are detected in 2 or 3 electron cyclotron emission (ECE) [27] channels on both the low-ÆEeldand high-Æeldsides. The mode radial structure shown in Fig. 6(a) clearly exhibits a ballooning character. This feature is also seen in the external magnetic measurement as shown in Fig. 3(c). These modes are peaked at the location of the high pressure gradient, as depicted in Fig. $6(\mathrm{~b})$. Stability analysis using both a full kinetic code [11] and a two-Øuid model [29] shows that, due to the strong local pressure gradient, the plasma is unstable to the kinetic MHD-ballooning modes (KBM). Study of similar KBMs observed in TFTR supershots (D-only and D-T plasmas) has been describẹ in Ref. [30]. In contrast to the beta-driven Alfven eigenmodes (BAE) [31] which have an Alfven frequency scaling, these modes have real frequencies which scale with $\omega \simeq \omega_{* p i} / 2$ (Ref. [30]), where $\omega_{* p i}$ is the ion-diamagnetic frequency. This scaling is qualitatively consistent with $\mathrm{KBM}$ theory [10].

\section{Particle orbit simulation}

Particle simulation using the ORBIT code [32] has been carried out for the single KBM mode $(n=6)$ case and brieØy reported in Ref. [11]. The mechanism 
of resonance-induced loss was demonstrated in the simulation. Similar particle simulation for the multiple mode case $(n=6-11)$ is reported here. Realistic geometry, $q(r)$, and KBM mode structure (Fig. 6) are used. The wave-particle resonant interaction is the same as the single-mode case. The lost particles are counter moving (opposite to the plasma current direction) passing particles initially located at a smaller minor radius. The wave-particle resonance condition in the plasma frame can be written as $n \phi-m_{d} \theta-\omega_{M H D} t=$ const., where $m_{d}=m, m \pm 1$. For a counter moving passing particle, $\phi=-\omega_{t} t, \theta=-\omega_{t} t / q$, where $\omega_{t} \sim\left|v_{\|}\right| / R$ is the toroidal transit frequency. The resonant condition becomes

$$
\omega_{M H D} \simeq\left(m_{d} / q-n\right) \omega_{t} .
$$

Figure 7 shows a typical lost alpha guiding center trajectory. This type of trajectory matches the measured escaping alpha parameters observed at the $90^{\circ}$ detector [energy and pitch angle $\left(=v_{\|} / v\right)$ ] [11]. A striking feature is that the wave-particle interaction time is very short comparing with the transit time. This is due to the large alpha orbit drift and localization of the MHD modes. Alpha particles with $E \sim 3.5 \mathrm{MeV}$ experience in each transit a large range of $q$ values. An example is shown in Fig. 8(a). They interact with KBMs only when they pass through the modes at small values of $r$ and $q$. During the brief interaction time $(\sim 2 \mu \mathrm{sec})$, the particles undergo a random-walk-like process as shown in Fig. 8(b). For those particles that lose energy in this process the accumulated changes in pitch angle can Anallycause a transition to a trapped orbit lost from the plasma. The alpha loss process revealed in this simulation tells us that multiple MHD modes at different radii or a more global mode such as the global TAE will be more dangerous than the localized mode(s) because the loss rate depends on the wave-particle interaction time. 
The alpha loss enhancement factor has also been simulated. In the simulation, 10000 particles, all at $3.5 \mathrm{MeV}$ with an isotropic pitch distribution, are followed for 9000 transit times $(\simeq 10 \mathrm{~ms})$. The six modes with $n=6-11$ and amplitude $\tilde{B} / B \simeq 0.5-2 \times 10^{-4}$ (based on Fig.6) were used in the simulation. We compared the number of lost particles both with and without the MHD mode present. We found that the loss with KBM present to be about twice the loss without the modes, which agrees with the measurement. This result quantitatively conÆrmsour basic observation that the enhanced loss is due to high $n$ KBMs.

\section{CONCLUSIONS}

Alpha-driven TAEs were observed during the post-beam phase of certain TFTR D-T discharges, as predicted by theory. Detailed data analysis shows that an elevated central $q$ signiÆcantlyreduced the $\beta_{\alpha}$ threshold for the $\alpha$-TAE excitation. The importance of low central magnetic shear (related to high $q_{0}$ ) can be qualitatively explained by the fact that the low central shear minimizes the radiative damping and continuum damping. Identißecationof the mode location and amplitude, measurement of the $q$ proßleand self-consistent transport simulations have been performed. For the Ersttime, all these experimental results provide an opportunity to benchmark the alpha-driven TAE theory. Initial numerical analysis from NOVA-K showed encouraging agreement with observations, e.g., TAE frequency, dominant mode number $(n=3)$, importance of the central $q$ proÆle,etc. But there are other observations which remain to be clariÆed.For example, the poloidal mode structure shows an anti-ballooning asymmetry, the order of appearance of different $n$ TAEs is not always the same, etc. Also, at present, due to the weakness of the $\alpha$-TAE, no correlated alpha-loss was observed. 
SigniÆcantalpha-loss correlated with high- $n(\geq 6)$ KBMs has been observed in other high-performance D-T discharges. Particle simulation using the measured mode parameters (frequency, radial structure, amplitude) showed that the waveparticle resonance can indeed cause the observed loss. The loss is primarily caused by the wave-particle interaction in both velocity and real space. In a large volume and high current tokamak such as ITER, this type of interaction may not cause a direct loss of alphas to the wall when the mode is core localized (since the alpha banana orbit is smaller than the plasma radius). The same argument is expected to hold for the $\alpha$-TAE, e.g., the core localized TAE should not be as dangerous as the global TAE. However, such MHD-induced alpha redistribution may change the alpha heating proÆleor reduce the fusion ignition margin in a reactor. 


\section{ACKNOWLEDGMENTS}

The authors would like to acknowledge useful discussions with R. Hawryluk, W. Heidbrink, J. Manickam and M. Zarnstorff. One of the authors (Z. Chang) would like to thank for fruitful discussions with the late Professor S.-T. Tsai. This research is sponsored by the U. S. Department of Energy under Contract No. DEAC02-76-CHO-3073. 


\section{References}

[1] ITER-JCT and Home Teams, Plasma Phys. Control. Fusion 37, A19 (1995).

[2] H. P. Furth, R. J. Goldston, S. J. Zweben, and D. J. Sigmar, Nucl. Fusion 30, 1799 (1990).

[3] C. Z. Cheng, L. Chen, and M. S. Chance, Ann. Phys. (NY) 161, 21 (1985);

C. Z. Cheng and M. S. Chance, Phys. Fluids 29, 3695 (1986).

[4] C. Z. Cheng, H. L. Berk, D. Borba, B. Breizman, R. Budny, R. H. Bulmer, J. Candy, D. S. Darrow, A. Fasoli, E. D. Fredrickson, G. Y. Fu, R. J. Goldston, N. Gorelenkov, G. Huysmans, W. Kerner, H. Kimura, S. V. Konovalov, Y. Kusama, J. Manickam, R. Nazikian, G. H. Neilson, W. M. Nevis, T. Ozeki, L. D. Pearlstein, S. Putvinskii, M. H. Redi, F. Romanelli, M. N. Rosenbluth, S. Sharapov, D. A. Spong, K. Tobita, J. W. Van Dam, G. Vlad, R. B. White, K. L. Wong, V. Wong, F. Zonca, and S. J. Zweben, TMEnegetic particle physics issues for ITER, Plasma Physics and Controlled Nuclear Fusion Research, Proceedings of the Sixteenth International Conference, 1996 (International Atomic Energy Agency, Vienna, in press), IAEA-CN-64/FP-23.

[5] E. Fredrickson, Z. Chang, R. Budny, C. Z Cheng, J. Dunlap, G. Y. Fu, A. Janos, E. Mazzucato, K. McGuire, R. Nazikian, K. L. Wong, and S. Zweben, in Proceeding of the 21st EPS Conference on Controlled Fusion and Plasma Physics, Vol. 18B Part I p. 246, 1994.

[6] S. J. Zweben, R. V. Budny, C. Z. Cheng, E. D. Fredrickson, G. Y. Fu, D. R. Mikkelsen, G. L. Schmidt, S. D. Scott, D. A. Spong, C. E. Bush, Z. Chang, D. S. Darrow, R. J. Fonck, L. R. Grisham, E. Mazzucato, R. Nazikian, 
D. K. Owens, H. K. Park, S. F. Paul, J. F. Schivell, J. D. Strachan, E. J. Synakowski, G. Taylor, and K. M . Young, Nucl. Fusion 36, 987 (1996).

[7] S. H. Batha, F. M. Levinton, D. A. Spong, R. V. Budny, Z. Chang, D. S. Darrow, E. D. Fredrickson, G. Y. Fu, E. Mazzucato, R. Nazikian, and S. J. Zweben, Nucl. Fusion 35, 1463 (1995).

[8] G. Y. Fu, C. Z. Cheng, R. Budny, Z. Chang, D. S. Darrow, E. Fredrickson, E. Mazzucato, R. Nazikian, K. L. Wong, and S. Zweben, Phys. Plasmas 3, 4036 (1996).

[9] R. Nazikian, S. H. Batha, M. G. Bell, R. E. Bell, R. V. Budny, C. E. Bush, Z. Chang, Y. Chen, C. Z. Cheng, D. Darrow, H. H. Duong, P. C. Efthimion, E. Fredrickson, G. Y. Fu, N. N. Gorelenkov, B. LeBlanc, F. M. Levinton, R. P. Majeski, E. Mazzucato, S. S. Medley, H. K. Park, M. P. Petrov, D. A. Spong, E. J. Synakowski, G. Taylor, S. von Goeler, R. B. White, K. L. Wong, and S. Zweben, ${ }^{\mathrm{TM}}$ Observatiomf alpha-driven toroidal Alfven eigenmodes in TFTR DT plasmas, in Ref. 4, IAEA-CN-64/A2-4.

[10] An incomplete list of references on KBM theory: W. M. Tang, et al., Nucl. Fusion 20, 1439 (1980); C. Z. Cheng, Phys. Fluids 25, 1020 (1982); J. Wieland and L. Chen, Phys. Fluids 28, 1359 (1985); H. Biglari and L. Chen, Phys. Rev. Lett. 67, 3681 (1991); S.-T. Tsai and L. Chen, Phys. Fluids B 5, 3284 (1993); W. M. Tang, G. Rewoldt, C. Z. Cheng, and M. S. Chance, Nucl. Fusion 25, 151 (1985).

[11] Z. Chang, R. Budny, L. Chen, D. Darrow, E. Fredrickson, A. Janos, D. MansÆeld,E. Mazzucato, K. M. McGuire, R. Nazikian, G. Rewoldt, J. D. 
Strachan, W. M. Tang, G. Taylor, R. B White, S. Zweben, and TFTR Group, Phys. Rev. Lett. 76, 1071 (1996).

[12] C. Z. Cheng, Phys. Rep. 211, 1 (1992).

[13] D. A. Spong, C. L. Hedrick, and B. A. Carreras, Nucl. Fusion 35, 1687 (1995).

[14] F. M. Levinton, G. M. Gammel, R. Kaita, H. W. Kugel, and D. W. Roberts, Rev. Sci. Instrum. 61, 2914 (1990).

[15] R. V. Budny, Nucl. Fusion 34, 1247 (1994) and references therein.

[16] E. Fredrickson, R. Colchin, K. McGuire, W. Morris, and N. Sauthoff, Rev. Sci. Instrum. 57, 2084 (1986).

[17] Z. Chang, E. D. Fredrickson, S. J. Zweben, H. Park, R. Nazikian, E. Mazzucato, S. Batha, M. G. Bell, R. V. Budny, C. E. Bush, D. S. Darrow, D. Ernst, G. Y. Fu, R. J. Hawryluk, K. W. Hill, J. Hosea, A. C. Janos, D. L. Jassby, D. W. Johnson, L. C. Johnson, F. M. Levinton, D. K. MansÆeld, K. M. McGuire, D. R. Mikkelsen, D. Mueller, D. K. Owens, A. Ramsey, S. A. Sabbagh, E. J. Synakowski, H. Takahashi, G. Taylor, M. E. Thompson, R. M. Wieland, K. L. Wong and M. C. Zarnstorff, Nucl. Fusion 35, 1469 (1995).

[18] H. L. Berk, J. W. Van Dam, D. Borba, J. Candy, G. T. A. Huysmans, and S. Sharapov, Phys. Plasmas 2, 3401 (1995).

[19] G. Y. Fu, C. Z. Cheng, R. Budny, Z. Chang, D. S. Darrow, E. Fredrickson, E. Mazzucato, R. Nazikian, and S. Zweben, Phys. Rev. Lett. 75, 2336 (1995). 
[20] G. Y. Fu, Y. Chen, R. Budny, Z. Chang, C. Z. Cheng, D. S. Darrow, E. Fredrickson, E. Mazzucato, R. Nazikain, W. Park, R. White, K. L. Wong, Y. Wu, S. Zweben, D. A. Spong, H. Kimura, T. Ozeki, M. Saigusa, M. S. Chu, W. W. Heidbrink and E. J. Strait, TMRecenprogress in linear and nonlinear studies of toroidal Alfven eigenmode, in Ref. 4, IAEA-CN-64/D2-6.

[21] F. M. Levinton, M. C. Zarnstorff, S. H. Batha, M. Bell, R. E. Bell, R. V. Budny, C. Bush, Z. Chang, E. Fredrickson, A. Janos, J. Manickam, A. Ramsey, S. A. Sabbagh, G. L. Schmidt, E. J. Synakowski, and G. Taylor, Phys. Rev. Lett. 754417 (1995).

[22] E. F. Fredrickon, M. G. Bell, R. V. Budny, Z. Chang, C. Z. Cheng, G. Y. Fu, E. Mazzucato, R. Nazikian, A. C. Janos, K. M. McGurie, R. Majeski, C. K. Phillips, G. Schilling, G. Taylor, and J. R. Wilson, Nucl. Fusion 35, 1457 (1995).

[23] K. L. Wong, R. J. Fonck, S. F. Pual, D. R. Roberts, E. D. Fredrickson, R. Nazikian, H. K. Park, M. Bell, N. L. Bretz, R. Budny, S. Cohan, G. W. Hammett, F. C. Jobes, D. M. Meade, S. S. Medley, D. Mueller, Y. Nagayama, D. K. Owens, and E. J. Synakowski, Phys. Rev. Lett. 66, 1874 (1991).

[24] D. S. Darrow, S. J. Zweben, Z. Chang, C. Z. Cheng, E. D. Fredriclson, E. Mazzucato, R. Nazikian, C. K. Phillips, S. Popovichev, M H. Redi, R. B. White, J. R. Wilson, and K. L. Wong, TMObservationsof neutral beam and ICRF tail ion losses due to Alfven modes in TFTR, submitted to Nucl. Fusion.

[25] D. MansÆeld, J. D. Strachan, M. G. Mell, S. D. Scott, R. Budny, E. S. Marmar, J. A. Snipes, J. L. Terry, S. Batha, R. E. Bell, M. Bitter, C. E. 
Bush, Z. Chang, D. S. Darrow, D. Ernst, E. Fredrickson, B. Grek, H. W. Herrmann, K. W. Hill, A. Janos, D. L. Jassby, F. C. Jobes, D. W. Johnson, L. C. Johnson, F. M. Levinton, D. R. Mikkelsen, D. Mueller, D. K. Owens, H. Park, A. T. Ramsey, A. L. Roquemore, C. H. Skinner, T. Stevenson, B. C. Stratton, E. Synakowski, G. Taylor, A. Von Halle, S. Von Goeler, K. L. Wong, and S. J. Zweben, Phys. Plasmas 2, 4252 (1995).

[26] S. J. Zweben, R. L. Boivin, C. S. Chang, G. W. Hammett, and H. E. Mynick, Nucl. Fusion 31, 2219 (1991).

[27] A. Cavallo, R. C. Cutler, and M P. McCarthy, Rev. Sci. Instrum. 59, 889 (1988).

[28] S. J. Zweben, D. S. Darrow, H. W. Herrmann, S. Batha, R. Budny, C.S. Chang, Z. Chang, E. Fredrickson, D. Jassby, L. Johnson, F. Levinton, H. Mynick, D. Owens, J. Schivell, S. Scott, M. Redi, J. Strachan, K. Tobita, and K. Young, Nucl. Fusion 35, 893 (1995).

[29] L. Zakharov, R. Budny, Z. Chang, E. Fredrickson Triggering Disruptions in TFTR at High-beta . in Proc. 23th Europ. Conf. on Controlled Fusion and Plasma Physics, Kiev, Ukraine, Paper A-014 (1996).

[30] R. Nazikian, Z. Chang, E. Fredrickson, E. Mazzucato, S. Batha, R. Bell, R. Budny, C. Bush, C. Z. Cheng, A. Janos, F. Levinton, J. Manickam, D. MansÆeld,H. Park, G. Rewoldt, S. Sabbagh, E. J. Synakowski, W. Tang, G. Taylor, and L. E. Zakharov, Phys. Plasmas 3, 593 (1996).

[31] W. W. Heidbrink, E. J. Strait, M. S. Chu, and A. D. Ternbull, Phys. Rev. Lett. 71, 855 (1993). 
[32] R. B. White and M. S. Chance, Phys. Fluids 27, 2455 (1984); R. B. White, Phys. Fluids B 2, 845 (1990). 


\section{List of Figures}

1 Two types of plasmas where the $\alpha$-TAEs are observed. The solid curves are for the high- $q_{0}$ plasma and the dash curves for the low$q_{0}$ plasma. (a) D-T Neutral beam power. (b) Fusion power. (c) Central $q$. The TAEs are observed in the shaded post-beam phase. The $n=3$ TAE amplitudes (d) and frequencies (e) are measured from magnetic coils. . . . . . . . . . . . . . 24

2 Time evolution of (a) Electron density at different radii, (b) magnetic spectrum contours of the edge Alfven frequency mode (AFM) and (c) TAE modes. An edge perturbation caused an immediate response in AFM frequency while the frequency of the $n=3 \mathrm{TAE}$ only correlates with the density changes around $0.25<r / a<0.45$. The TAE frequency evolution using the density at $r / a=0.34$ is shown in (c)....................... 25

3 Poloidal variation of the $\alpha$-TAE (a) shows a non-ballooning feature. As a comparison, the ICRF-TAE (b) with the same $n$ peaks at the low Æeld side, which is similar to the high $n$ kinetic ballooning mode case (c). . . . . . . . . . . . . . . .

4 (a) The $\alpha$-TAE plasmas do not have large $\beta_{\alpha}(0)$ in comparison with similar fusion power supershot plasmas. (b) The higher $q$ (lower shear) feature separates these plasmas from supershot regime. The TAE $\beta_{\alpha}(0)$ threshold reduces for high- $q_{0}$ plasmas. The exception in reversed shear cases indicates the importance of $q$ proÆleinstead of $q_{0}$. 
5 The observed alpha loss event (a) correlates with the occurence of high $n(>6)$ modes (b). The $\tilde{T}_{e} / T_{e}$ frequency spectrum is from an internal ECE channel at $r / a \simeq 0.40 . \ldots \ldots \ldots 28$

6 (a) High $n \mathrm{KBM}$ mode structure measured by multi-channel ECE diagnostic. These modes locate near the maximum normalized $\nabla \beta$ $(\alpha)$ region where the $q$ is around $1-1.5$ as shown in (b). . . .

7 A typical trajectory of an escaping alpha lost to the $90^{\circ}$ (bottom) detector, simulated using the ORBIT code. The counter-passing alpha particles interact with KBMs only on the low Æeldside. . . 30

8 The last few transit motions of an escaping alpha (a). Due to the large alpha orbit drift and narrow KBM structure, the wave-particle resonant interaction time is much shorter than the transit time as shown in (b). . . . . . . . . . . . . . . 31 


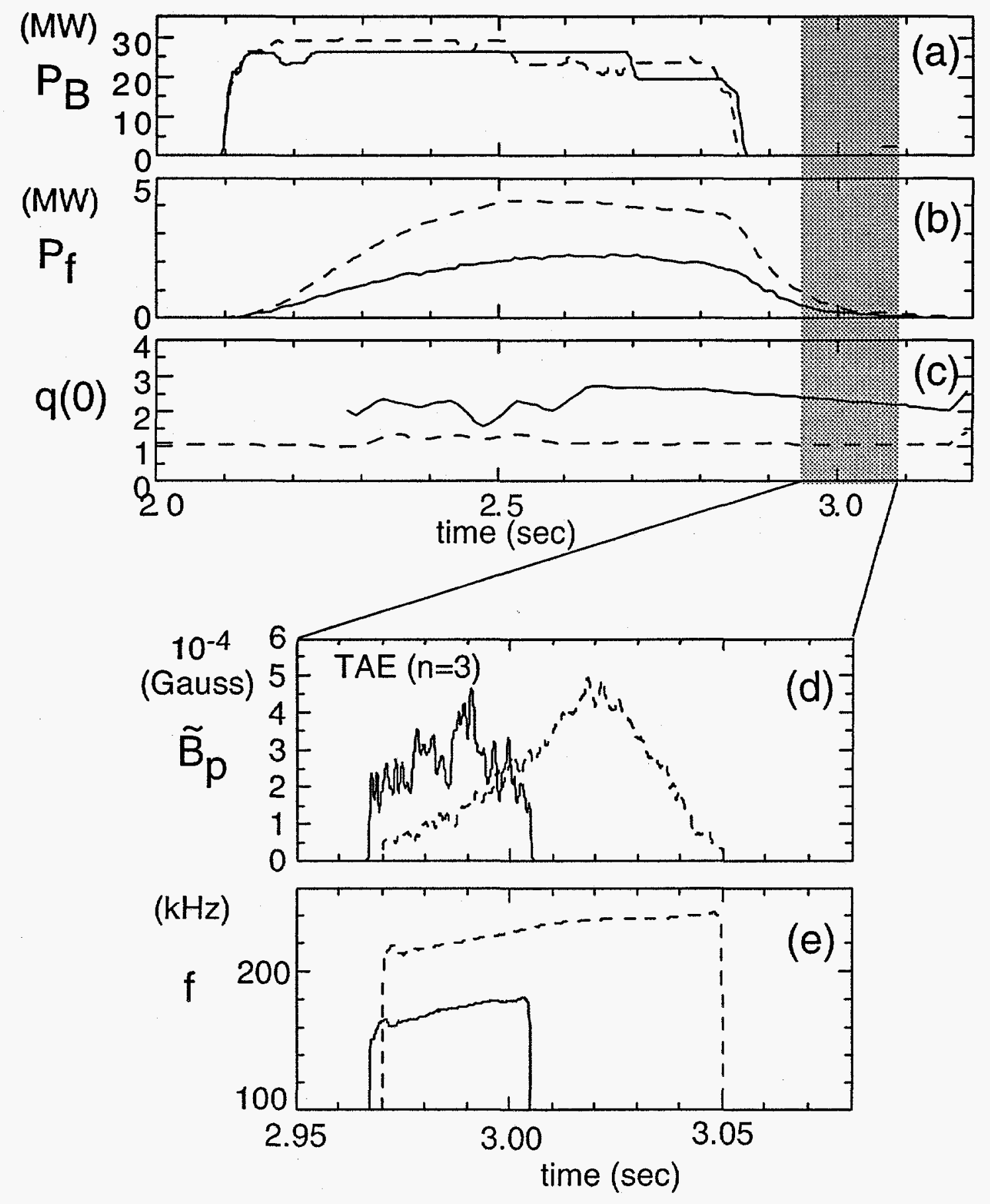

Z.Chang, Fig. 1 


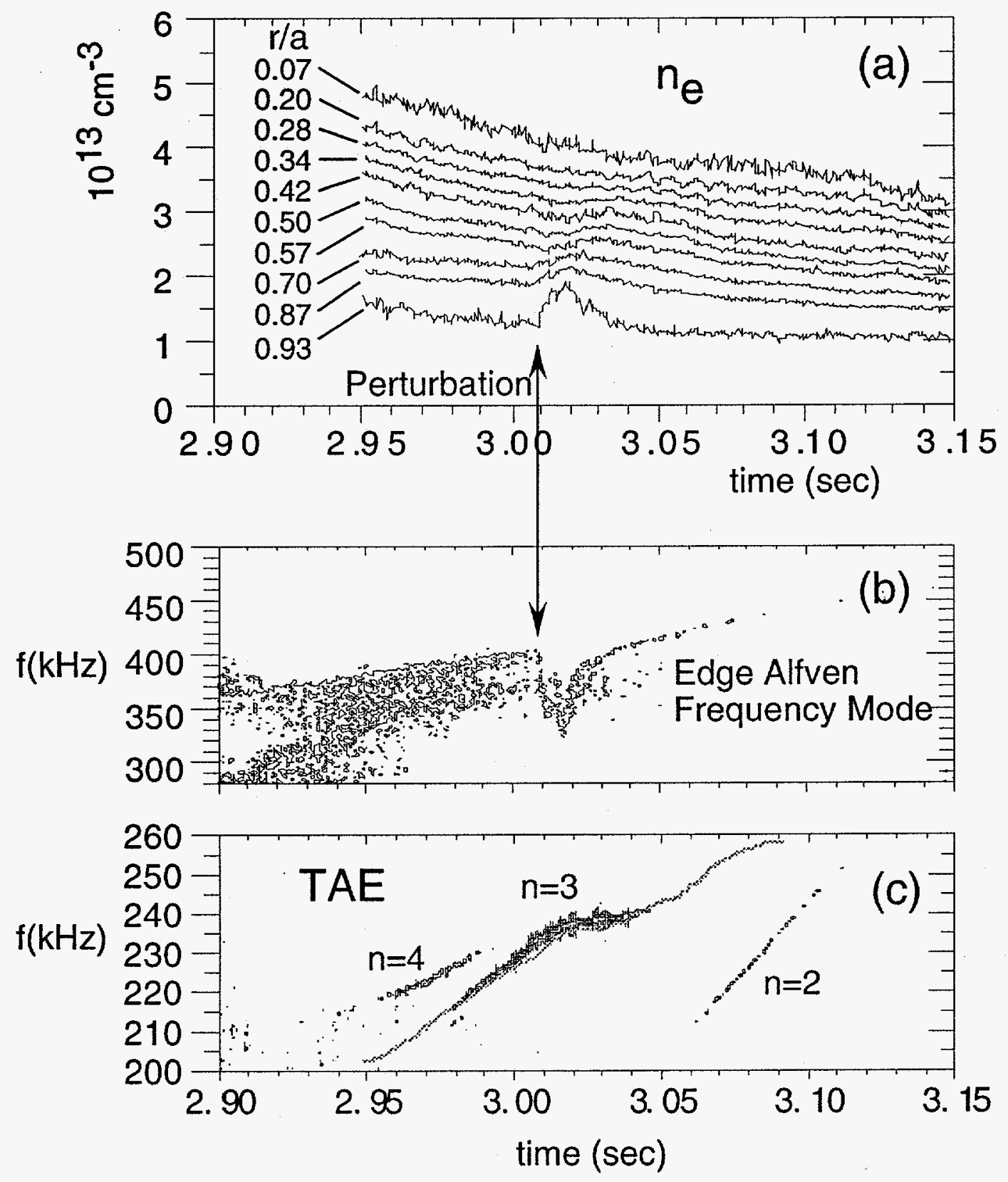

Z. Chang, Fig. 2 

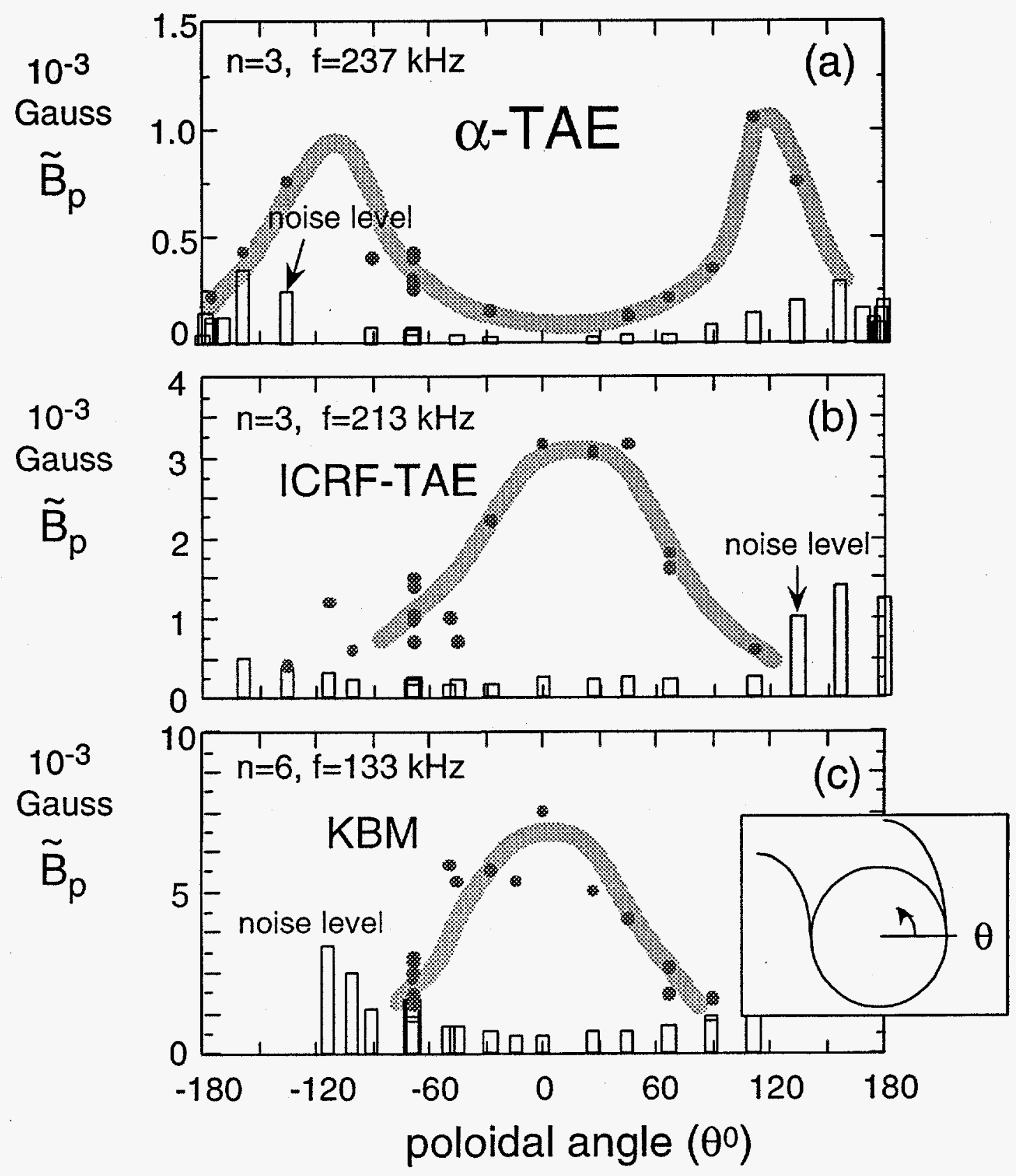

Z. Chang, Fig. 3 
(a)

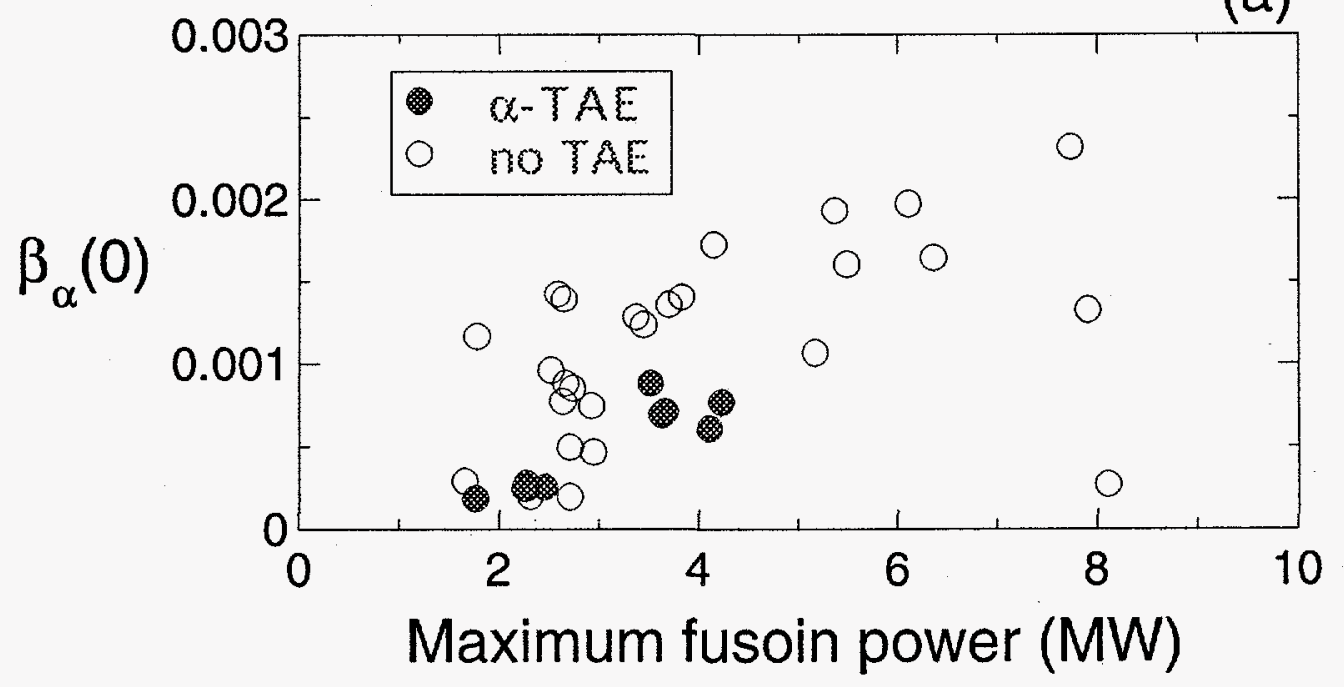

(b)

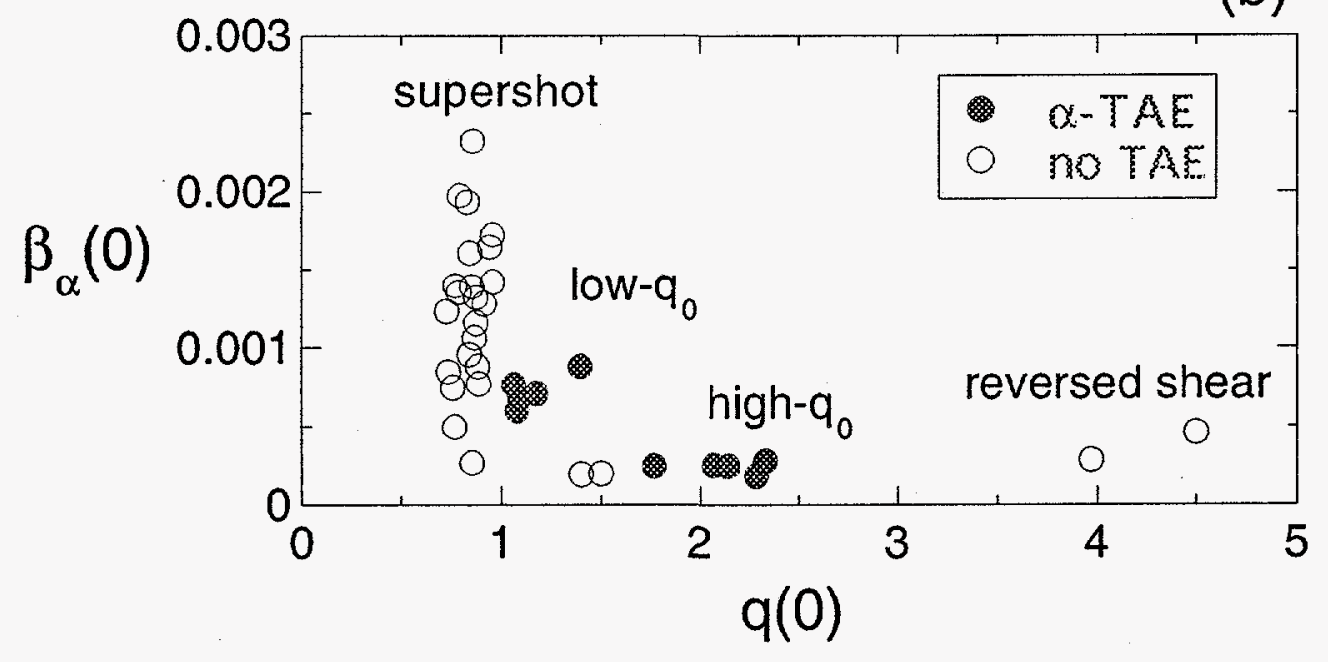

Z. Chang, Fig. 4 


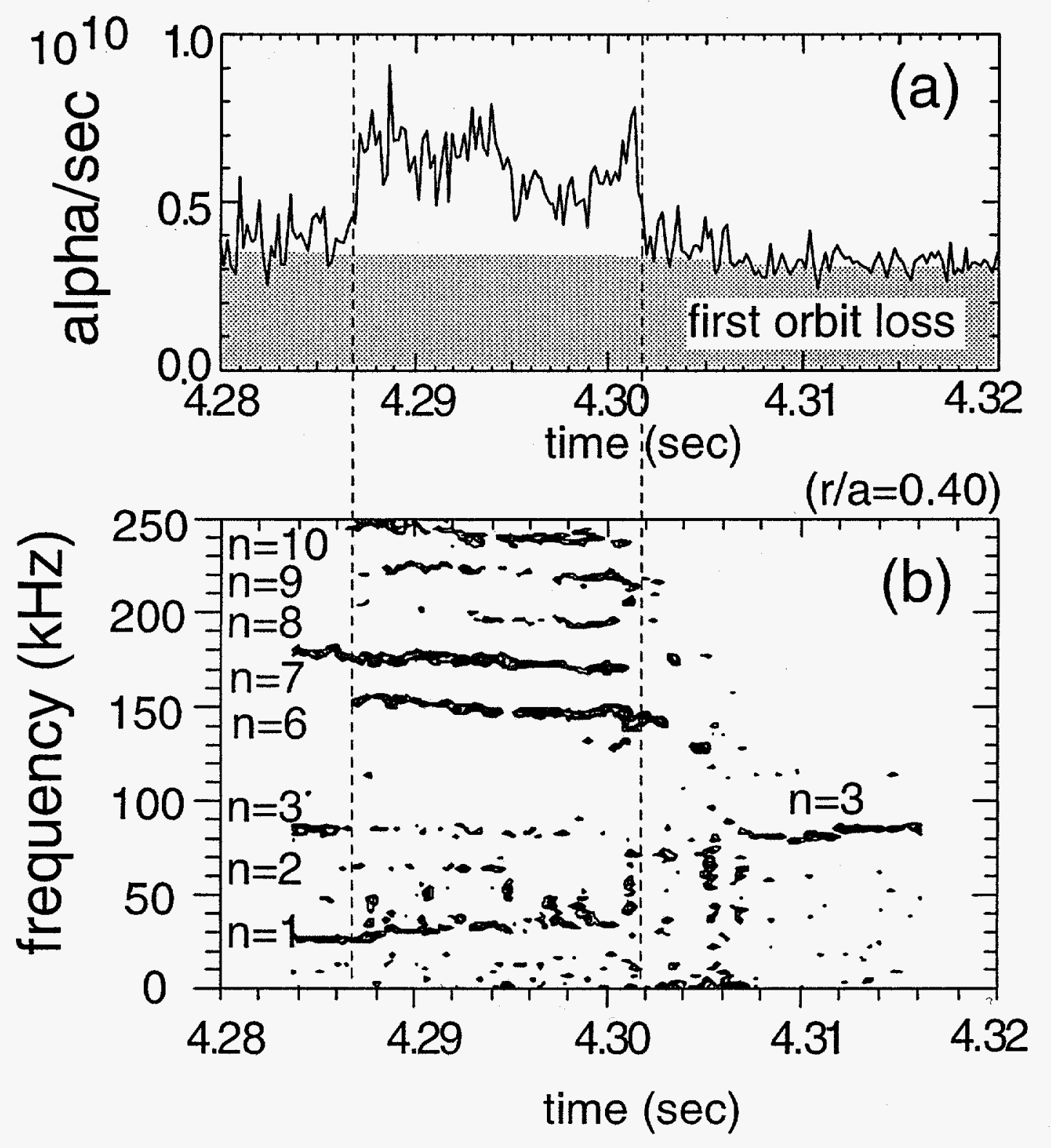

Z. Chang, Fig. 5 

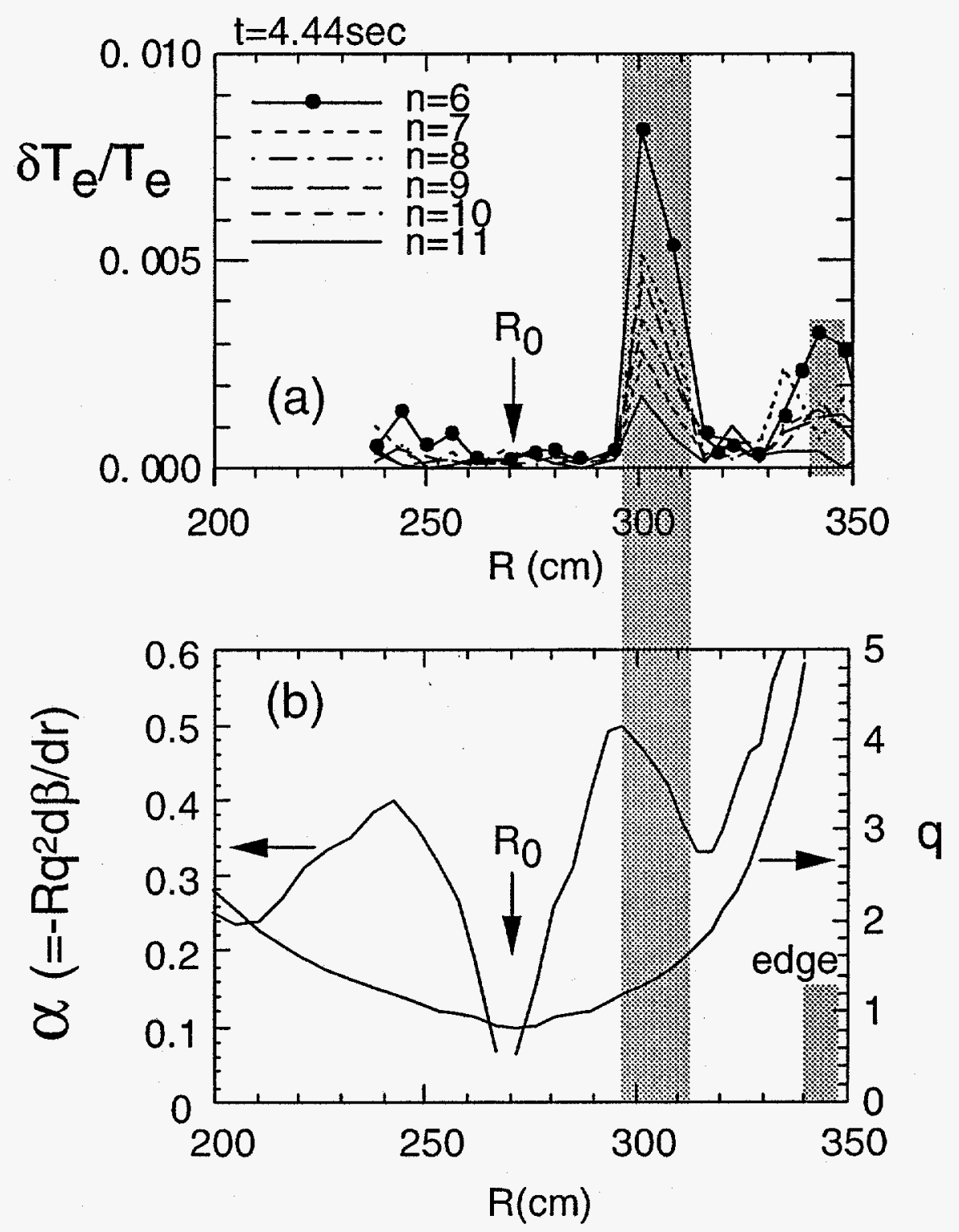

Z. Chang, Fig. 6 


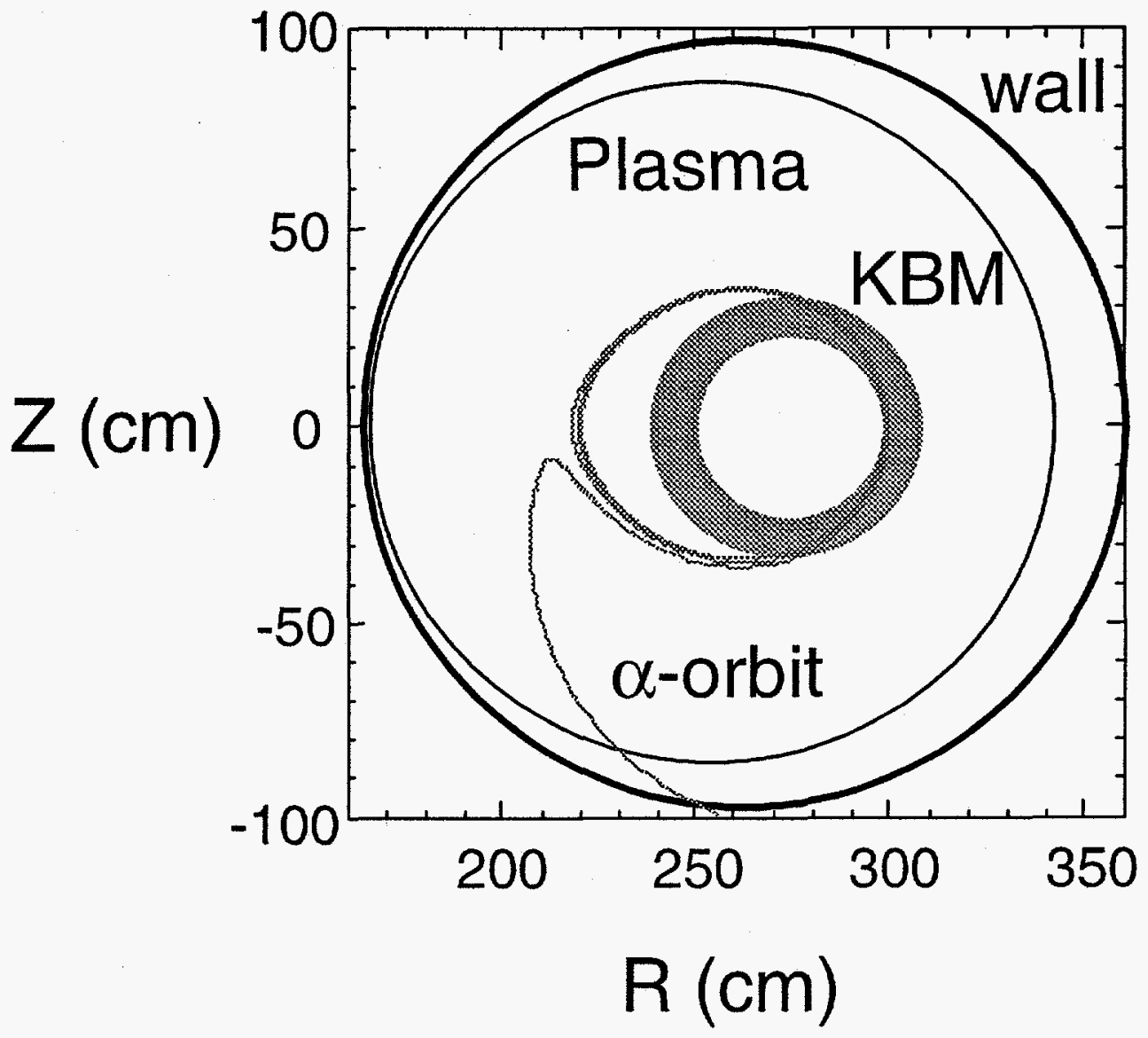

Z.Chang, Fig. 7 

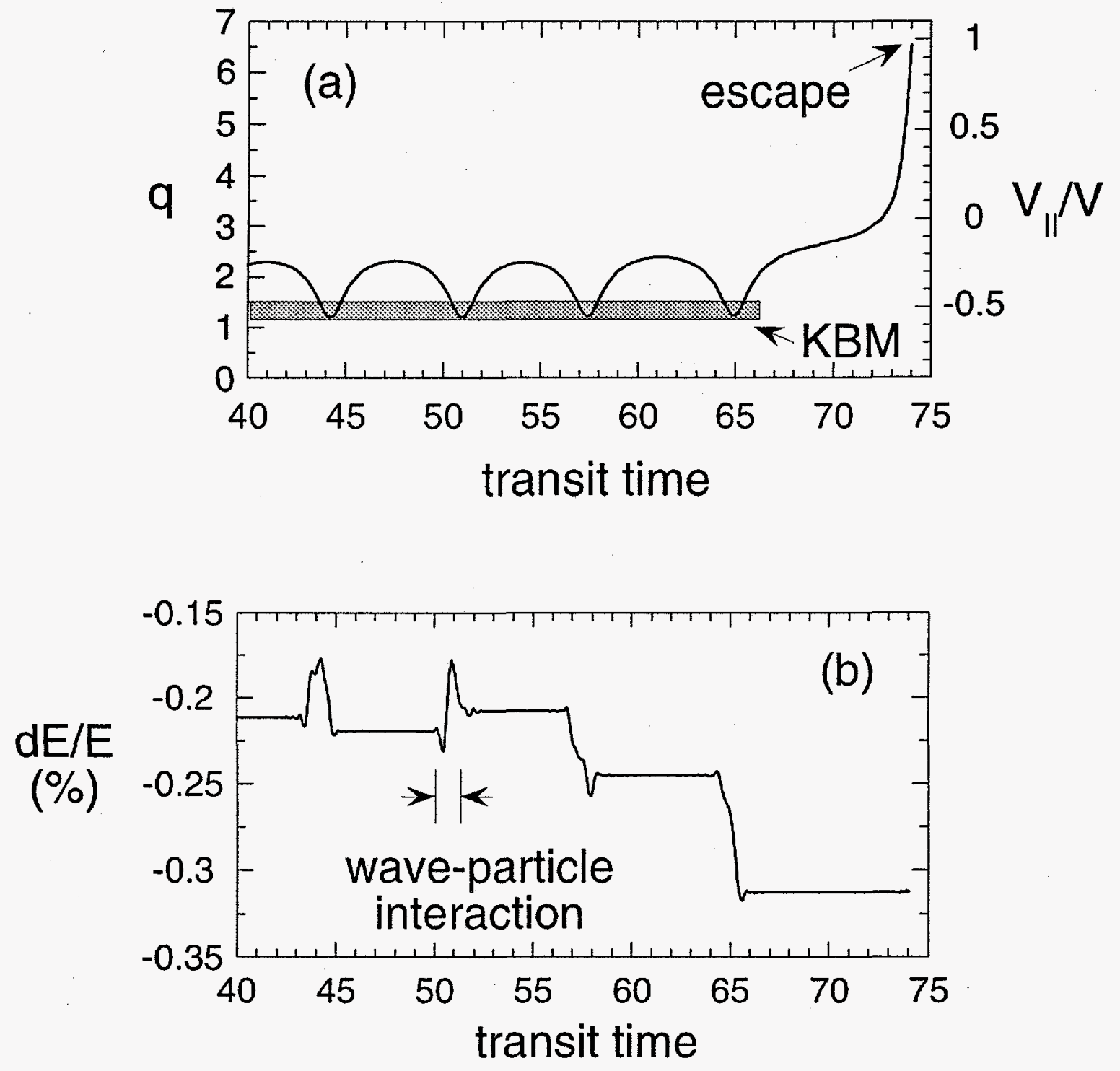

Z. Chang, Fig. \& 